\title{
Antioxidative and Hypoglycemic Effects of Delonix elata and Vachellia farnesiana Leaves Extracts on Streptozotocin-Induced Diabetic Male Rats
}

\author{
Sameera A. Alghamdi ${ }^{1,2}$ \\ ${ }^{1}$ Department of Biological Sciences, Faculty of Science, ${ }^{2}$ Princess Dr. Najla Bint Saud Al-Saud Center \\ for Excellence Research in Biotechnology, King Abdulaziz University, Jeddah, Saudi Arabia. \\ Received: 10 August 2019/ Accepted 05 Oct. 2019 / Publication date: 20 Oct. 2019
}

\begin{abstract}
Diabetes Mellitus (DM) is known to be a group of metabolic disorders characterized by an elevated glucose level. Plants are the most promising causes of new therapeutic agents. The usual usage of plant products for the managing of DM has grown up because of the nominal side-effects with the minimal economy as controlling of diabetes without the side-effects is a challenge. The drugs prepared from the plants may play a major role in the treatment. This study aims to inspect the hypoglycemic with antioxidant potentiality of leaves extract from Delonix elata (DELE) and Vachellia farnesiana (VFLE) in streptozotocin (STZ) male rats with DM. This study incorporates 80 Wistar male rats categorized into eight groups. Normal control rats were appeared in groupr1. Untreated DM rats termed as DM controls as in group 2. Groups 3-5 involve the DELE, VFLE and DELE plus VFLE as DM rats. Groups 6-8 were treated as normal rats with DELE, VFLE and DELE plus VFLE respectively. The DM control group inhibited decrease in body weight and increased in the serum levels of glucose, HbAlc, protein and lipid profiles, creatinine, BUN. ALT, AST and MDA, whereas, serum insulin, GPx and CAT levels were reduced. In Gr3-5 of DM rats, extracts disclosed clear influence at body weight, glucose, $\mathrm{HbA1c}$, protein and lipid profiles, liver and kidney functions parameter, and oxidative stress markers. The results revealed the extracts exhibited significant anti-oxidant and hypoglycemic activity which could be the appearance of pharmacologically active ingredients. However, these extracts can be applied alternatively in dealing DM and allied complications. In conclusion, the novel of these plant extracts further should be investigated to reconfirm for predicting their clinical potential as a phytomedicine for DM treatment.
\end{abstract}

Keywords: Diabetes, streptozotocin, Delonix elata, Vachellia farnesiana, antioxidant, blood, rat.

\section{Introduction}

Diabetes Mellitus (DM) is categorized as elevated serum glucose levels and known as the metabolic disorder (Baquer et al., 1998). Global prevalence of DM is rising profligately (Azizidoost et al., 2019). The World Health Organization (WHO) has reported that the Kingdom of Saudi Arabia (KSA) ranks second in the prevalence of DM in the Middle East region and seventh in the world (Robert et al., 2017). Oxidative stress is defined as imbalance between oxidants and anti-oxidants defense capacity of the body is recommended as optimal mechanism underlying complications with DM and other diseases (Atalay and Laaksonen, 2002). Numerous amendments in DM individuals are oxidative in nature and depend on enlarged oxidative stress (Baynes, 1991). The role of oxidative stress in the etiology of DM and its complications has been increasingly recognized (Brownlee, 2004; Wang et al., 2017; Jiang et al., 2018; Ito et al., 2019; Wang et al., 2019).

Streptozotocin (STZ, 2-deoxy-2 (3-(methyl-3-nitrosoureido) -Dglucopyranose) is a naturally occurring chemical, a broad-spectrum antibiotic that is particularly toxic to the insulin-producing $\beta$ cells of the pancreas. STZ is a synthetic antineoplastic agent and is used clinically for the treatment of metastatic islet cell carcinoma of the pancreas. STZ is commonly used to induce DM and it is a highly selective cytotoxic agent to insulin producing pancreatic islet $\beta$-cells and is shown to induce DM in various animal models including mice and rats. The chemical induction of DM with STZ has gained popularity because of the relative ease of rendering normal animals diabetic (Luippold et al., 2016; Abraham et al., 2107; Abdelhamid et al., 2108; Banerjee et al., 2019; Zhang et al., 2109).

Corresponding Author: Dr. Sameera A. Alghamdi, Department of Biological Sciences, Faculty of Science, ${ }^{2}$ Princess Dr. Najla Bint Saud Al-Saud Center for Excellence Research in Biotechnology, King Abdulaziz University, P.O. Box 8020, Jeddah 21589, Jeddah, Saudi Arabia. Email: saalghamdi17@gmail.com 
Currently, usage of common drugs for DM treatment is costly with strong side effects (Schuster et al., 2005). Globally, the prevalence rate is growing towards the herbal medicine in the human disorders (Azizidoost et al., 2019). Traditional herbal medicines are assumed to have less side effects for treating to DM (Yin et al., 2008). Quick rising need is required for improving new strategies for prevention of DM with limited side effects (Yuan et al., 2016; Khavandi et al., 2013). Present literature documents 800 plant species confirm hypoglycemic activity (Rajagopal and Sasikala, 2008). Delonix and Acacia are genera of flowering plants dispersed in throughout the Southern region of Saudi Arabia. Delonix elata is a species from Fabaceae family, Caesalpinioideae sub-family. D. elata is used for joint pains and in flatulence which has antiinflammatory, antirheumatic, antihyperlipidemic, antimicrobial, antinociceptive and antioxidant activity (Krishnappa et al., 2016). The leaf part was scientifically evidenced to have cytotoxic, hepatoprotective and free radical scavenging activity (Babu and Goud, 2018). Vachellia farnesiana (Acacia farnesiana synonym) plant species belongs to Leguminoseae family; known as medicinal plants used in folk medicinal practices. Additionally, the extracts attained from Acacia have formerly publicized antimicrobial, antihelminthic and antioxidant properties (Alonso-Diaz et al., 2010; Cuchillo et al., 2010; Sanchez et al., 2013; Delgadillo Puga et al., 2015; Afsar et al., 2019). The present study aims to explore probable antioxidative and antidiabetic activity of D. elata and $V$. farnesiana leaves extracts in male rats.

\section{Materials and Methods}

\section{Plant material}

The plant leaves (D. elata and V. farnesiana) were freshly collected from outskirts of Al-Baha region of Saudi Arabia. Collected freshly leaves were washed, dried to a constant weight and crushed to moderately soft powder. Two hundred and fifty grams of leaves powder were added to eight liters of hot water and mixed for $180 \mathrm{~min}$. The solutions for opted plants were boiled for an hour and cooled at room temperature. The decoction was filtered and the filtrates were evaporated to dryness under vacuum at $50{ }^{\circ} \mathrm{C}$ in a rotary evaporator. The dried residues were stored in airtight containers at $-20{ }^{\circ} \mathrm{C}$ pending further experimental use.

\section{Experimental animals}

Male albino Wistar rats with a body weight of 196-223 grams were used for this study. Animals were maintained at $20 \pm 1{ }^{\circ} \mathrm{C}$ with $65 \%$ of relative humidity with 12 hours of each dark and light cycle. Eating and drinking stuffs were supplied. The experiment was carried out as per King Abdulaziz University ethical committee.

\section{Induction of experimental DM}

Rats were fasted for DM induction for 12 hours without unrestricting to water. Freshly prepared STZ solution $(60 \mathrm{mg} / \mathrm{kg}$ body weight) in citrate buffer $(0.1 \mathrm{M} ; \mathrm{pH}-4.5)$ was inserted to overnight abstained rats. Diabetic state evaluated in STZ-treated rats by determining abstaining serum at 72 hours of post to STZ injection. Rats with blood glucose levels greater than $17 \mathrm{mmol} / \mathrm{L}$ were confirmed as diabetic models.

\section{Experimental treatments}

Normal and diabetic rats $(\mathrm{n}=10)$ were assigned into 8 groups. Normal rats (controls) are assigned in group1. Diabetic rats (controls) in group 2. Diabetic rats are categorized supplemented orally by DELE (group 3) and VFLE (group 4) of $300 \mathrm{mg} / \mathrm{kg}$ body weight/day. However, group 5 is combined combination of DELE $(150 \mathrm{mg} / \mathrm{kg})$ and VFLE $(150 \mathrm{mg} / \mathrm{kg})$ body weights/day. Normal rats of groups 6 and 7 are orally supplemented with DELE and VFLE of each $300 \mathrm{mg} / \mathrm{kg}$ body weight/day. Group 8 as combined combination is supplemented with DELE $(150 \mathrm{mg} / \mathrm{kg})$ and VFLE $(150 \mathrm{mg} / \mathrm{kg})$ body weights/day.

\section{Body weight}

After the efficacious indicational experiment of DM, body weights of rats (normal and diabetes) were measured using electronic weighing balance during day 1 and after completion of 6 weeks as final body weight. 


\section{Hematobiochemical assay}

After completion of 6 weeks, complete rats were fasted for 8 hours prior to blood samples collection, anesthetized and blood were drawn from orbital venous plexus. Blood samples were transferred in (1) heparinized blood samples were used for Hb1Ac tests. (2) Serum samples were unglued from non-heparinized blood sample centrifuged at $3000 \mathrm{rpm}$ for $10 \mathrm{~min}$ and used for serum glucose, total protein, albumin, lipid profile, AST, ALT, creatine, BUN measurements using Dimension Vista ${ }^{\circledR} 1500$ system, USA. As per Judzewitsch et al. (1982) was used to evaluate serum levels of insulin. Additionally, the levels of serum malondialdehyde (MDA), catalase (CAT) and glutathione peroxidase (GPx) were evaluated according to the methods of Ohkawa et al. (1979), Aebi (1984), and Paglia and Valentine (1967) respectively.

\section{Statistical analysis}

Statistical data were analyzed as mean \pm standard deviation of variables in different groups using ANOVA variance. Software (SPSS), version 22.0 was applied for performing statistics. The significance levels were tested at $P \leq 0.05$.

\section{Results}

The body weights of all the experimental groups are shown in Fig1. After six weeks, maximum increase of body weight obtained in nondiabetic rats of 8 group $(+47.7 \%)$ followed by groups 6 $(45.7 \%), 7(+45.1 \%)$ and $1(+42.1 \%)$. Treated diabetic rats with DELE, VFLE and DELE+VFLE showed mild increase in body weight gain which is reached $+16.3 \%$ (group 3) $+15.0 \%$ ( group4) and $+19.1 \%$ (group 5 ). The non-significant body weight gain was noted in diabetic rats of group 2 ($17.2 \%)$.

$$
\square 0 \text { Week } \square 6 \text { Weeks }
$$

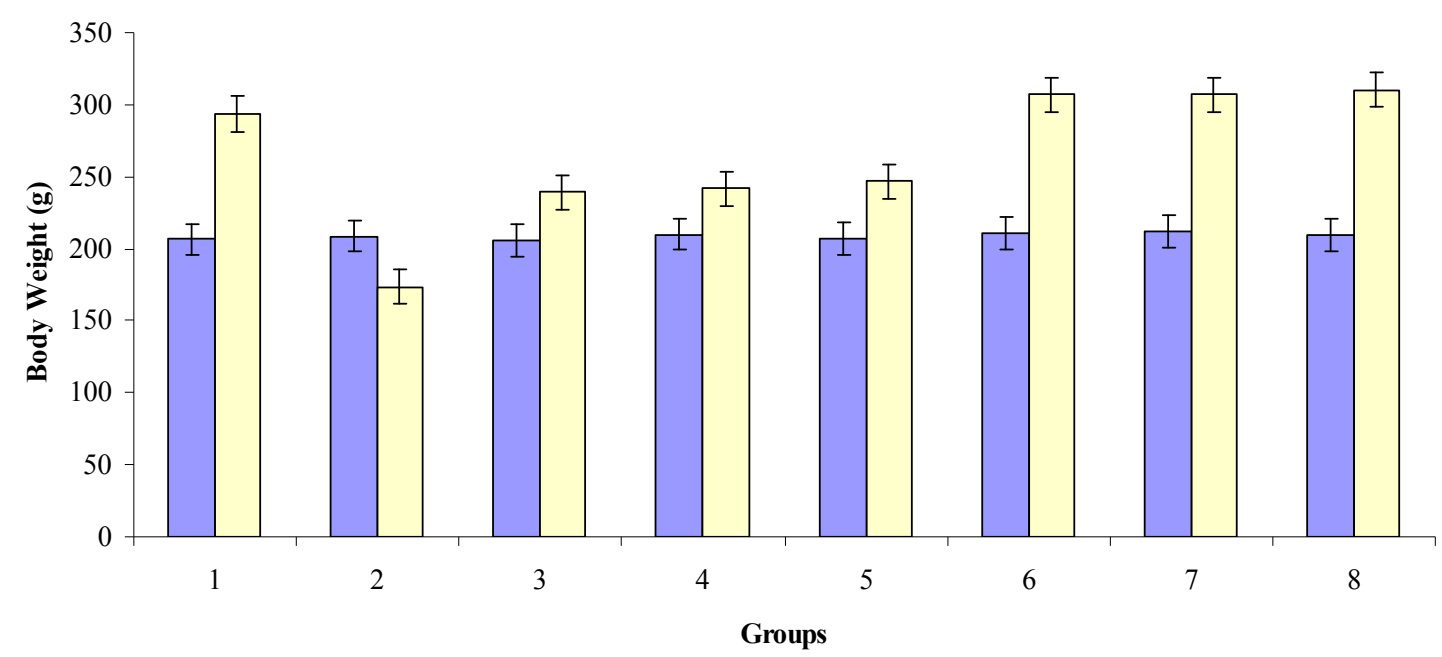

Fig. 1: Changes of body weight after six weeks in control (group 1), STZ (group 2), STZ plus DELE (group 3), STZ plus VFLE (group 4), STZ plus DELE and VFLE (group 5), DELE (group 6), VFLE (group 7), and DELE and VFLE (group 8) treated rats.

Fasting glucose, insulin and $\mathrm{HbA1c}$ values were showed in Fig 2 A-C. Statistical significance was observed in fasting glucose in diabetic rats of group $2(P \leq 0.000)$, group $3(P \leq 0.000)$, group 4 $(P \leq 0.000)$, and group $5(P \leq 0.000)$; whereas, insulin values were decreased in diabetic rats of group $2(P \leq 0.000)$, group $3(P \leq 0.000)$, group $4(P \leq 0.000)$ and group $5(P \leq 0.001)$. HbAlc values were statistically enhanced in diabetic rats of group $2(P \leq 0.000)$, group $3(P \leq 0.001)$, group $4(P \leq 0.000)$ and group $5(P \leq 0.001)$ compared with normal control rats of group 1 . 
A

$\square$ Control $\square$ STZ $\square$ STZ + DELE $\square$ STZ + VFEL $\square$ STZ + DELE +VFLE $\square$ DELE $\square$ VFLE $\square$ DELE + VFLE

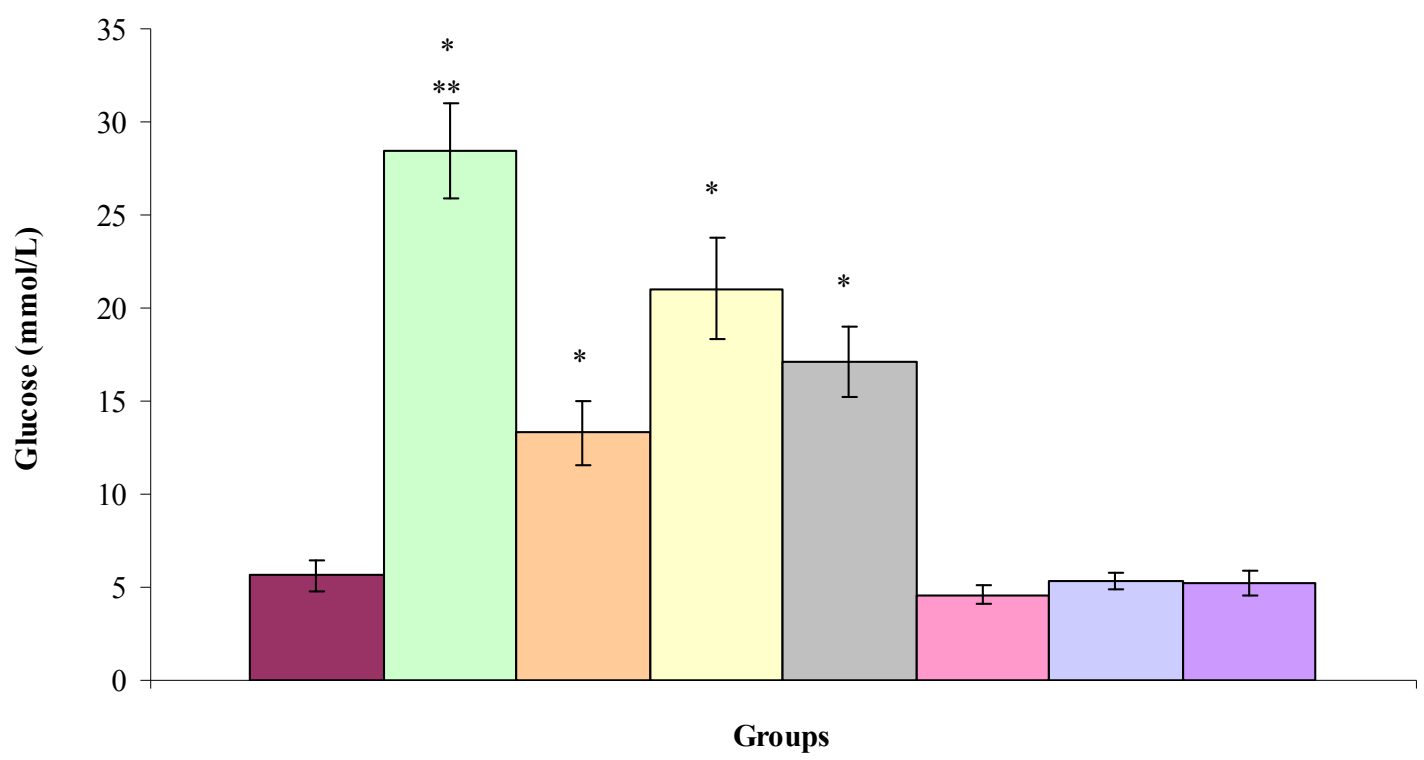

B

$\square$ Control $\square$ STZ $\square$ STZ + DELE $\square$ STZ + VFEL $\square$ STZ + DELE +VFLE $\square$ DELE $\square$ VFLE $\square$ DELE + VFLE

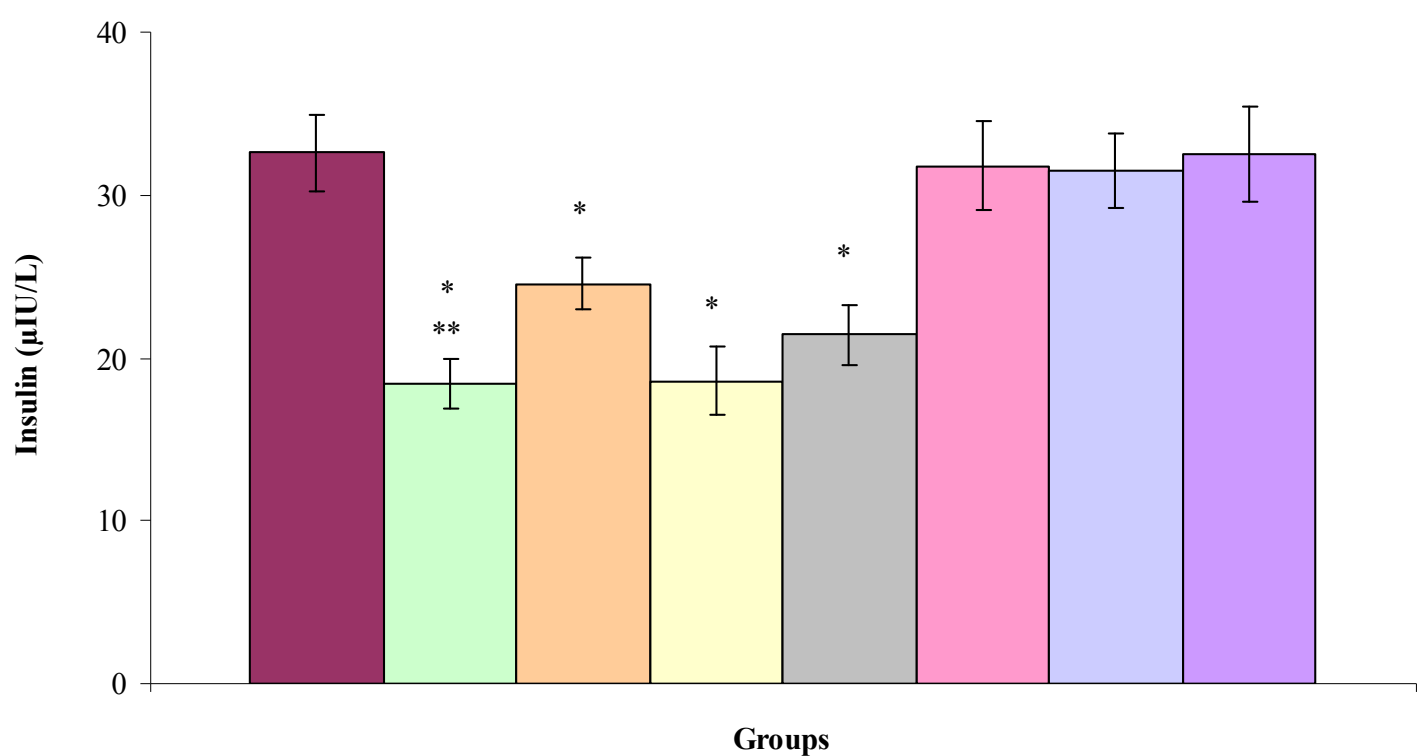


C

Control $\square$ STZ $\square$ STZ + DELE $\square$ STZ + VFEL $\square$ STZ + DELE +VFLE $\square$ DELE $\square$ VFLE $\square$ DELE + VFLE

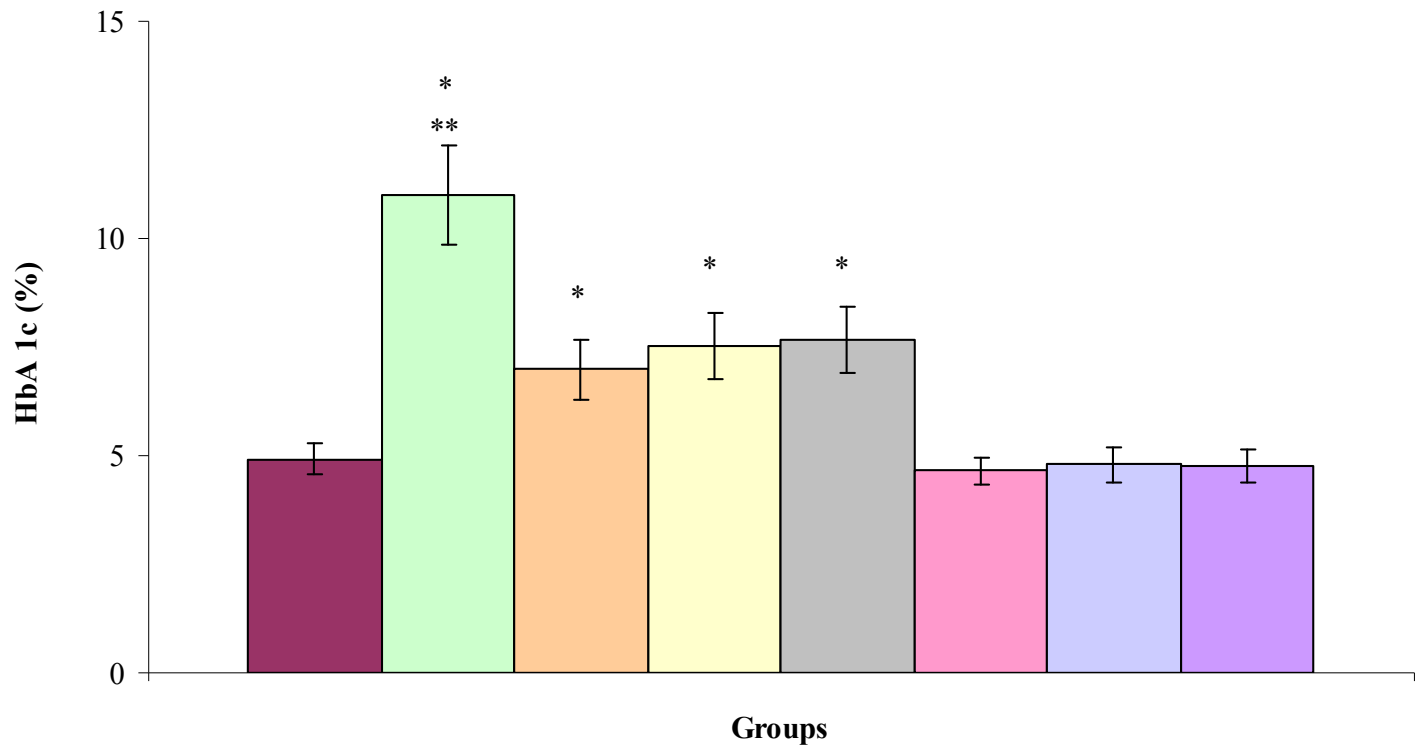

Fig. 2A-C: The levels of serum glucose (A), insulin (B) and HbA 1c (C) in control (group 1), STZ (group 2), STZ plus DELE (group 3), STZ plus VFLE (group 4), STZ plus DELE and VFLE (group 5), DELE (group 6), VFLE (group 7) and DELE plus VFLE (group 8) treated rats after six weeks.. Indicates a significant difference between control and treated groups. ${ }^{* *}$ Indicates a significant difference between group 2 and groups 3, 4, 5, 6, 7 and 8 .

The results of Table 1 show the levels of serum total protein, albumin, triglycerides and cholesterol. In comparison with normal control rats of group 1, the value of serum total protein was increased in diabetic rats of group $2(P \leq 0.001)$, while these parameters were not changed in other treated groups. Insufficient alteration was detected in serum albumin levels in all the treated groups equated with normal control rats of group 1. Remarkable elevation in triglycerides was observed in diabetic rats in groups $2(P \leq 0.001), 4(P \leq 0.02)$ and $5(P \leq 0.03)$. A significant increase in cholesterol levels were recorded in diabetic rats of groups $2(P \leq 0$. 004), $4(P \leq 0.03)$ and $5(P \leq$ 0.002).

Table 1: The values of serum total protein, albumin, triglycerides and cholesterol of control (group 1), STZ (group 2), STZ plus DELE (group 3), STZ plus VFLE (group 4), STZ plus DELE and VFLE (group 5), DELE (group 6), VFLE (group 7) and DELE plus VFLE (group 8) treated rats after six weeks.

\begin{tabular}{|c|c|c|c|c|}
\hline Parameters & $\begin{array}{c}\text { Total protein } \\
(\mathrm{g} / \mathrm{L})\end{array}$ & $\begin{array}{c}\text { Albumin } \\
(\mathrm{g} / \mathrm{L})\end{array}$ & $\begin{array}{c}\text { Triglycerides } \\
(\mathrm{mmol} / \mathrm{L})\end{array}$ & $\begin{array}{c}\text { Cholesterol } \\
(\mathrm{mmol} / \mathrm{L})\end{array}$ \\
\hline Control & $55.33 \pm 2.88$ & $9.83 \pm 1.47$ & $0.60 \pm 0.05$ & $0.97 \pm 0.13$ \\
\hline STZ & $66.17 \pm 4.26^{\mathrm{ab}}$ & $7.51 \pm 1.34$ & $1.48 \pm 0.34^{\mathrm{ab}}$ & $1.60 \pm 0.25^{\mathrm{ab}}$ \\
\hline STZ + DELE & $56.67 \pm 4.80$ & $10.17 \pm 1.33$ & $0.64 \pm 0.11$ & $1.17 \pm 0.12$ \\
\hline STZ + VFLE & $58.40 \pm 5.16$ & $7.33 \pm 1.51$ & $0.88 \pm 0.22^{\mathrm{a}}$ & $1.22 \pm 0.17^{\mathrm{a}}$ \\
\hline STZ + DELE and VFLE & $61.17 \pm 4.40$ & $8.83 \pm 1.94$ & $0.98 \pm 0.30^{\mathrm{a}}$ & $1.25 \pm 0.14^{\mathrm{a}}$ \\
\hline DELE & $54.67 \pm 4.23$ & $9.33 \pm 1.03$ & $0.53 \pm 0.09$ & $0.86 \pm 0.15$ \\
\hline VFLE & $55.12 \pm 3.31$ & $10.10 \pm 1.47$ & $0.61 \pm 0.10$ & $0.96 \pm 0.19$ \\
\hline DELE + VFLE & $55.33 \pm 3.50$ & $9.67 \pm 1.63$ & $0.59 \pm 0.04$ & $0.87 \pm 0.12$ \\
\hline
\end{tabular}

Data represent the means \pm SD of 6 animals per group. ${ }^{a}$ Indicates a significant difference between control and treated groups. ${ }^{b}$ Indicates a significant difference between group 2 and groups 3, 4, 5, 6, 7 and 8 .

Table 2 demonstrates the ALT, AST, creatinine and BUN levels. A significant increase was observed in ALT levels in groups $2(P \leq 0.000), 4(P \leq 0.003)$ and $5(P \leq 0.000)$ when compared with normal control rats. Diabetic rats of groups $2(P \leq 0.000), 3(P \leq 0.03), 4(P \leq 0.000)$ and $5(P \leq$ $0.001)$ showed statistically increase of serum AST. Serum creatinine levels were found to be increase 
in diabetic rats of groups $2(P \leq 0.002), 4(P \leq 0.05)$ and $5(P \leq 0.02)$. BUN levels were significantly evoked in diabetic rats of groups $2(P \leq 0.000), 4(P \leq 0.000)$ and $5(P \leq 0.001)$ when compared with normal control rats of group1.

Table 2: The values of serum ALT, AST, creatinine and BUN of control (group 1), STZ (group 2), STZ plus DELE (group 3), STZ plus VFLE (group 4), STZ plus DELE and VFLE (group 5), DELE (group 6), VFLE (group 7) and DELE plus VFLE (group 8) treated rats after six weeks.

\begin{tabular}{lcccc}
\hline Preatments & $\begin{array}{c}\text { ALT } \\
(\mathbf{U} / \mathbf{L})\end{array}$ & $\begin{array}{c}\text { AST } \\
(\mathbf{U} / \mathbf{L})\end{array}$ & $\begin{array}{c}\text { Creatinine } \\
(\boldsymbol{\mu m o l} / \mathbf{L})\end{array}$ & $\begin{array}{c}\text { BUN } \\
(\mathbf{m m o l} / \mathbf{L})\end{array}$ \\
\hline Control & $45.17 \pm 3.06$ & $109.23 \pm 5.50$ & $35.63 \pm 2.46$ & $6.68 \pm 0.37$ \\
STZ & $131.22 \pm 13.52^{\mathrm{ab}}$ & $215.50 \pm 9.35^{\mathrm{ab}}$ & $57.17 \pm 7.91^{\mathrm{ab}}$ & $18.57 \pm 3.46^{\mathrm{ab}}$ \\
STZ + DELE & $48.33 \pm 4.14$ & $124.17 \pm 10.16^{\mathrm{a}}$ & $38.18 \pm 6.70$ & $7.22 \pm 1.50$ \\
STZ + VFLE & $67.77 \pm 9.27^{\mathrm{a}}$ & $165.00 \pm 13.22^{\mathrm{a}}$ & $43.52 \pm 6.42^{\mathrm{a}}$ & $11.53 \pm 1.48^{\mathrm{a}}$ \\
STZ + DELE and VFLE & $66.83 \pm 3.76^{\mathrm{a}}$ & $155.67 \pm 18.53^{\mathrm{a}}$ & $45.62 \pm 5.733^{\mathrm{a}}$ & $11.40 \pm 1.83^{\mathrm{a}}$ \\
DELE & $46.33 \pm 2.89$ & $110.33 \pm 2.42$ & $34.83 \pm 2.87$ & $6.73 \pm 0.64$ \\
VFLE & $46.00 \pm 3.06$ & $113.00 \pm 4.23$ & $35.77 \pm 2.05$ & $6.66 \pm 0.74$ \\
DELE + VFLE & $45.83 \pm 3.490$ & $112.33 \pm 6.09$ & $36.17 \pm 2.52$ & $6.25 \pm 0.87$ \\
\hline
\end{tabular}

Data represent the means \pm SD of 6 animals per group. ${ }^{a}$ Indicates a significant difference between control and treated groups. ${ }^{\mathrm{b}}$ Indicates a significant difference between group 2 and groups 3, 4, 5, 6, 7 and 8 .

Notable enhancement in the value of serum MDA was observed in diabetic rats of groups $2(P \leq$ $0.000), 3(P \leq 0.001), 4(P \leq 0,000)$ and $5(P \leq 0.002)$ (Fig. $3 \mathrm{~A})$.

Significant declines in the value of serum CAT were observed in diabetic rats of groups $2(P \leq 0.000)$, $3(P \leq 0.001), 4(P \leq 0.001)$ and $5(P \leq 0.01)$ (Fig. 3B). Figure $3 \mathrm{C}$ showed that the values of serum GPx were statistically inhibited in diabetic rats of groups $2(P \leq 0.000), 3(P \leq 0.003), 4(P \leq 0.001)$ and $5(P \leq 0.004)$. As shown in Figures 2 and 3, and Tables 1 and 2, the values of all measured biochemical parameters were remarkably unchanged in normal rats supplemented with DELE (group 6), VFLE (group 7) and DELE plus VFLE (group 8) compared with normal control rats.

\section{A}

$\square$ Control $\square$ STZ $\square$ STZ + DELE $\square$ STZ + VFEL $\square$ STZ + DELE +VFLE $\square$ DELE $\square$ VFLE $\square$ DELE + VFLE

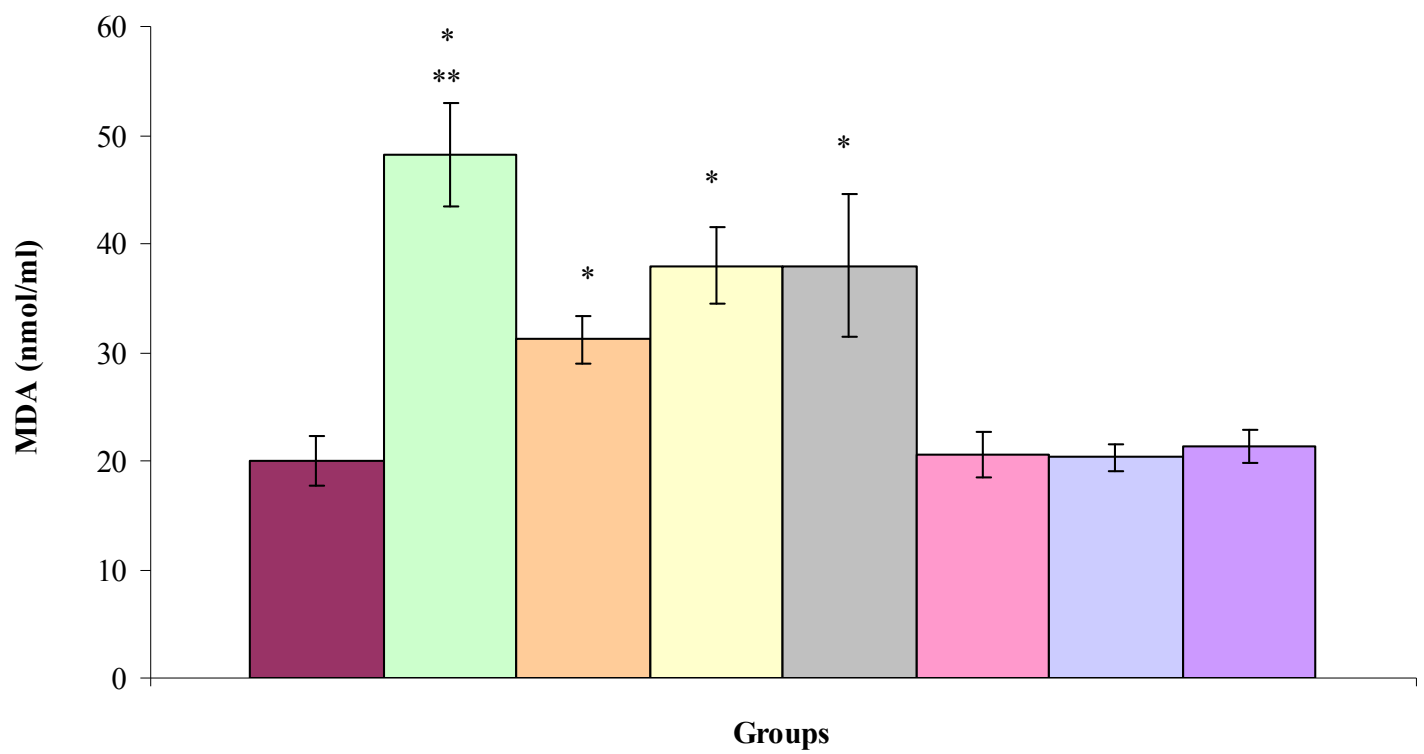


B

$\square$ Control $\square$ STZ $\square$ STZ + DELE $\square$ STZ + VFEL $\square$ STZ + DELE +VFLE $\square$ DELE $\square$ VFLE $\square$ DELE + VFLE

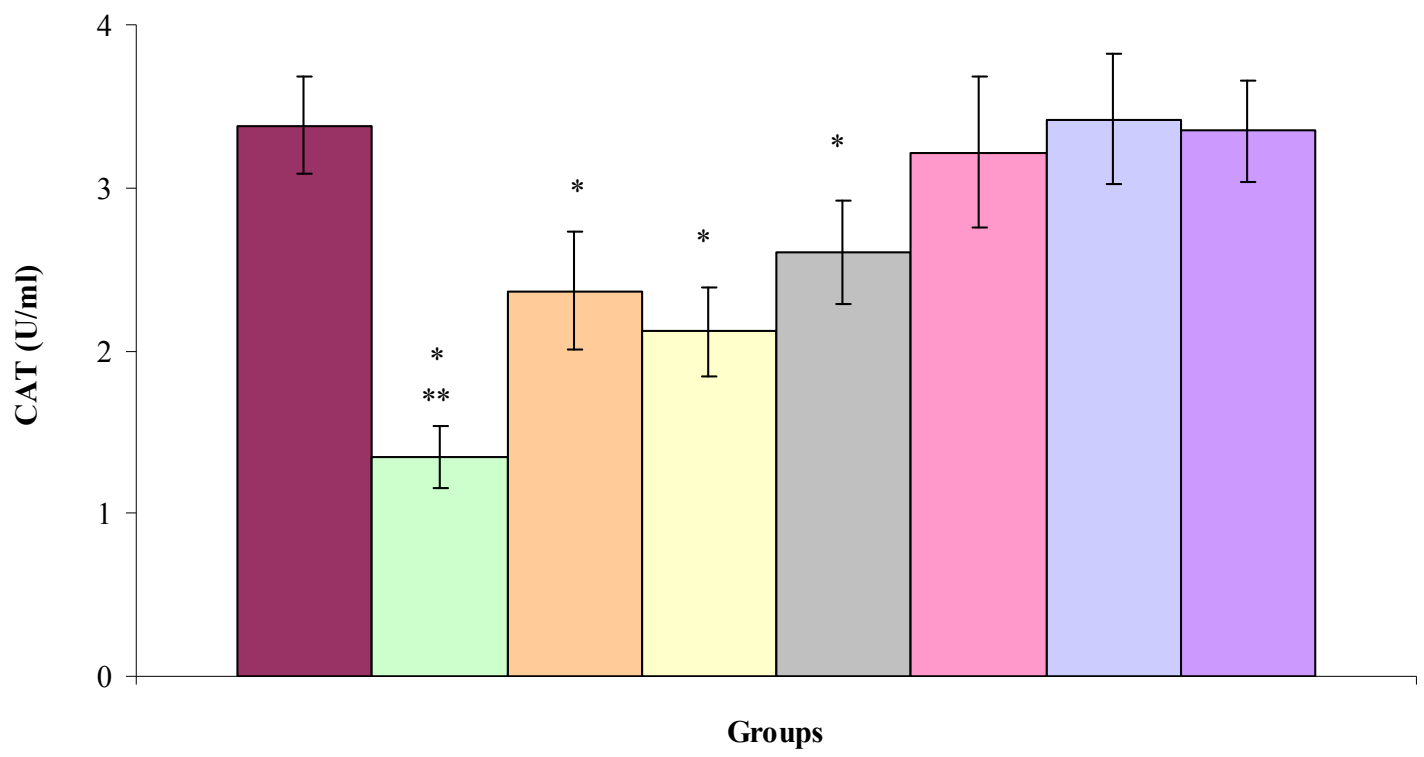

C

$\square$ Control $\square$ STZ $\square$ STZ + DELE $\square$ STZ + VFEL $\square$ STZ + DELE +VFLE $\square$ DELE $\square$ VFLE $\square$ DELE + VFLE

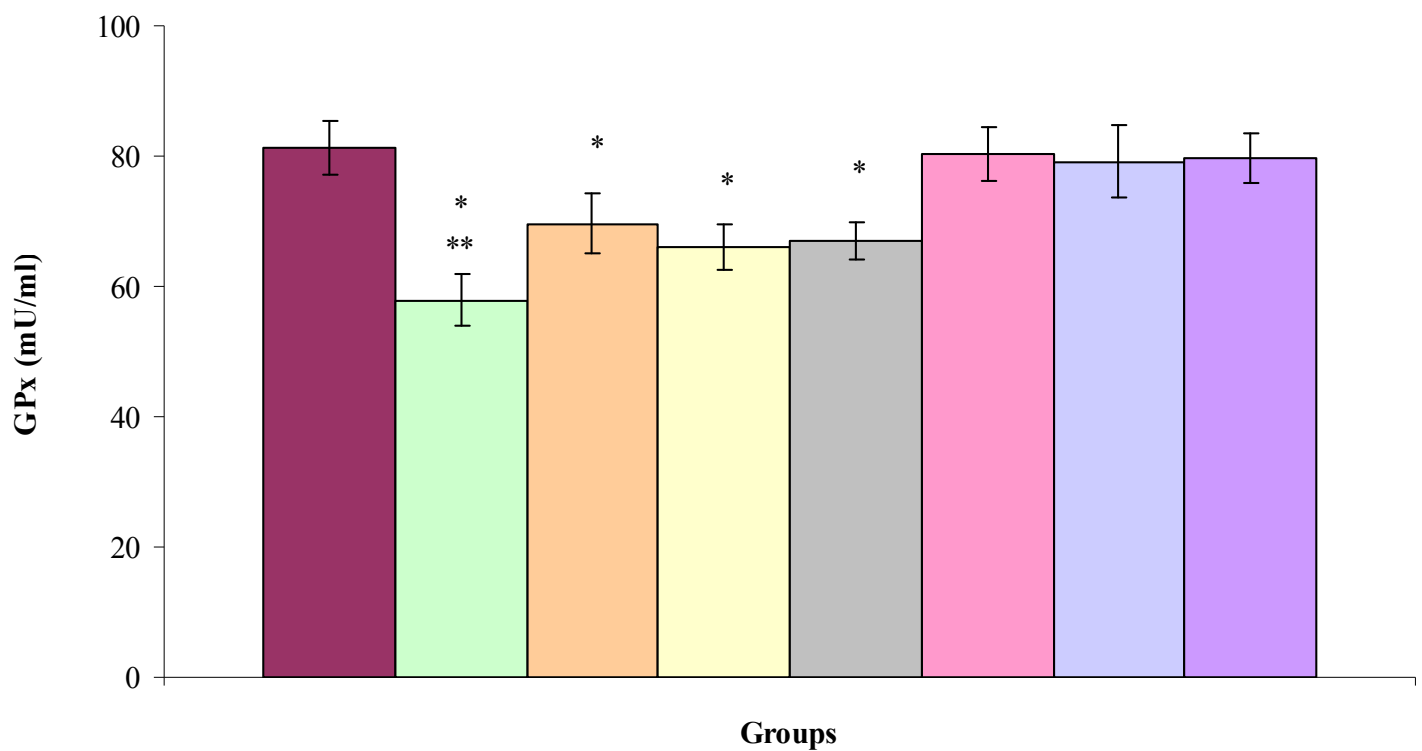

Fig. 3A-C: The levels of serum MDA (A), CAT (B) and GPx (C) in control (group 1), STZ (group 2), STZ plus DELE (group 3), STZ plus VFLE (group 4), STZ plus DELE and VFLE (group 5), DELE (group 6), VFLE (group 7) and DELE plus VFLE (group 8) treated rats after six weeks.*Indicates a significant difference between control and treated groups. **Indicates a significant difference between group 2 and groups 3, 4, 5, 6, 7 and 8 .

\section{Discussion}

DM is known to be as non-modifiable disease ripens throughout the world. DM can lead to T1DM, T2DM with micro and macrovascular complications (Tian et al., 2017). In the current era, medicinal plants are gaining immense important because of their various photoconstituents with 
distinctive properties. The present study confirms induction in STZ leads to decrease in body weight gain and insulin value associated with increases glucose, $\mathrm{HbAlc}$ and total protein, triglycerides and cholesterol values in normal control diabetic rats. The function of STZ has an ability to hoard in pancreatic $\beta$-cells through glucose transporter 2 (GLUT-2). Furthermore, STZ causes a generation of reactive oxygen species (ROS) in $\beta$-cells. Pancreatic $\beta$-cells consists of weak antioxidant may damage nucleic acid, apoptosis and destruction of $\beta$-cells (Lenzen et al., 2008; Garcia-Lafuente et al., 2009). This theory confirms increase in the glucose and HbAlc values and decrease in insulin. HbA1c is the gold standard test to confirm the minimum of 90 days of average value of glucose levels and high levels confirm the poor control of glucose levels (Mahajan and Mishra, 2011).

STZ-induced DM is associated with characteristic loss in body weight inversely relate to raise in muscle wasting which occurs due to loss in tissue proteins (Swanston-Flatt et al., 1990). Preservation of catabolism occurs due to decrease in body weight, which could be due to the proteolytic breakdown of tissue proteins in amino-acids further oxidized as cells were not able to fascinate blood glucose for the source of metabolic energy. However, these amino acids may be utilized as gluconeogenic precursors in liver. Additionally, glycogenolysis and lipolysis might contribute towards decrease in body fat in DM cases (Franz et al., 2003; Postie et al., 2004; Sekar et al., 2005). The reduction in body weight of DM rats is could be the muscle loss and adipose tissues that dependent to insulin for using of glucose as fuel (Ashrafi et al., 2017).

In the pathogenesis of DM, lipids play a vibrant role; associated with major abnormalities in fatty acid metabolism (Tomkin, 2008). Hypertriglyceridemia and hypercholesterolemia are known to be the common cause of lipid abnormalities in DM (Leiter et al., 2006). A significant raise in triglycerides and cholesterol can be accredited to endogenous changes in lipid homeostasis cause with DM. Mahe et al. (1995) documented hypercholesterolemia in STZ-induced DM rats results from increase in intestinal absorption and synthesis in cholesterol. Abnormal serum lipids levels in DM rats might be due to disturbance in the regulation of the activity of the hormone-sensitive enzyme, lipase, by insulin due to its deficiency or absence. In diabetic condition, the concentration of serum free acids is elevated as a result of free fatty acid outflow from fat deposited, where the balance of the free fatty acid esterification- triglyceride lipolysis cycle is displaced in favour of lipolysis (Maghrain et al., 2004; Sirwalker et al., 2004). Elevation in both triglycerides and cholesterol levels could be the increase in cholesterogenesis, uptake in fatty acids and triglycerides deposits in liver (Babu et al., 1997; Rajasekaran et al., 2006).

The present significant increase in the levels of serum ALT and AST as markers of liver function, and creatinine and BUN as markers of kidney function in the diabetic control rats suggested that DM could induce hepatic and renal injuries. Liver and kidney are the major organs connected with biochemical pathways to regulate homeostasis. The enhanced levels of ALT and AST might be leakage in the enzymes and functional loss integrity of cell membrane in liver (Swamy et al., 2018). Diabetic hyperglycemia induces growth in creatinine, BUN and uric acid, is considered to be significant markers of renal dysfunction (El-Demerdash et al., 2005; Saeed et al., 2008). Abnormal levels creatinine and urea in DM rats were compared with controls is an indication of renal dysfunction and metabolic disturbance induced by STZ-DM (Helal et al., 2014).

In this study, MDA levels were increased in STZ-induced DM rats and CAT and GPx levels were lowered when compared with normal control group. The increase in MDA levels confirms oxidative stress sustained sufficiently could cause free radical in cellmembrane; thus, MDA is confirmed as good indicator for assessing oxidative stress in degenerative diseases as DM (Padalkar et al., 2012). The serum antioxidant enzyme activities (CAT and GPx) were lowered in DM rats which attributed to induction of hyperglycemia; main cause for regulation in free radical levels in ROS which can lead to lipid peroxidation and altered antioxidant defense and further impair in glucose metabolism (Balasubhashini et al., 2004). Hyperglycemia in DM causes oxidative stress through persuading free radical formation via glucose autoxidation, polyol pathway and non-enzymatic glycation of proteins (Obrosova et al., 2002). Abnormal normal levels of free radical can harm the cellular organelles and enzymes (Maritim et al., 2003). Further, formation of free radicals was grown and antioxidant potential was lowered in DM rats. Imbalance of both oxidant and antioxidant defense system was seen in modification of antioxidant factors such as MDA, CAT and GPx which were used as markers in the oxidative stress studies (Al-Rawi et al., 2011; Kulkarni et al., 2014; Omodanisi et al., 2017; Oguntibeju, 2019). 
The current results indicate the treatment with extracts significantly reduced the alterations of body weight and biochemical parameters induced by STZ. The present results indicate that these extracts decrease glucose and $\mathrm{HbAlc}$ levels and increase insulin level in diabetic rats. Moreover, protein and lipid profiles, liver and kidney markers and oxidative stress markers were improved in diabetic rats supplemented with leaves extracts. Hypoglycemic effect of certain plants has been ascribed to insulin effect by growth in pancreatic secretion of insulin through $\beta$-cells (Pari and Amarnath Satheesh, 2004). Some plant extracts are known to inhibit hepatic production of glucose (Eddouks et al., 2003). DM treatment with plant medicines has proven safer than the synthetic drugs (Yeh et al., 2003). Oxidative stress in DM has been documented to co-exist with decrease in endogenous anti-oxidant status and is caused by dysfunction in pancreatic $\beta$-cells (Kajimoto and Kaneto, 2004); plays a major role in DM pathogenesis and its complications such as atherosclerosis, nephrotic, neurological and renal diseases (Sepici-Dincel et al., 2007). Oxidative stress is suggested as mechanism underlying DM and diabetic complications, which results from an imbalance between radical generating and radical scavenging systems (Neethu et al., 2014). The current study confirmed that oral administration of DELE, VFLE and DELE+VFLE prevented oxidative stress in STZ-induced diabetic rats. The protective action of these extracts possibly via their antioxidant effect in reversing biochemical alteration induced by DM. Therefore, the hypoglycemic properties of these extract can be credited to rich antioxidant contents. Additionally, the probable possible mechanism of hypoglycemic effects on these extracts might be affecting the pancreatic insulin to lowers the glucose levels. Moreover, the present study results also in agreement with benefiting the leaves extracts for management of DM. Further research is required to support the use of natural products in managing DM. Finally, the extracts should be further investigated to isolate the active constituents for hypoglycemic activity and development of new drugs for DM treatment.

\section{References}

Abdelhamid, A.M., R.R. Abdelaziz and H.A.A. Salem, 2018. Vildagliptin/pioglitazone combination improved the overall glycemic control in type I diabetic rats. Can. J. Physiol. Pharmacol., 96: 710-718.

Abraham, B.F., S.A. Olarewaju, A. Ronke and A.E. Oladipo, 2017. Antidiabetic and antidyslipidemic activities of the aqueous extract of Cochlospermum planchonii leaves in streptozotocin-induced diabetic rats. Iran. J. Med. Sci., 42: 553-560.

Aebi, H., 1984. Catalase in vitro. Methods Enzymol., 105: 121-126.

Alonso-Díaz, M.A., J.F. Torres-Acosta, C.A. Sandoval-Castro and C.M. Capetillo-Leal, 2010. Polyphenolic compounds of nutraceutical trees and the variability of their biological activity measured by two methods. Trop Subtrop. Agroecosyst., 12: 649-656.

Al-Rawi, N.H., 2011. Oxidative stress, antioxidant status and lipid profile in the saliva of type 2 diabetics. Diab. Vasc. Dis. Res., 1: 22-28.

Afsar, T., S. Razak and A. Almajwal, 2019. Effect of Acacia hydaspica R. Parker extract on lipid peroxidation, antioxidant status, liver function test and histopathology in doxorubicin treated rats. Lipids Health Dis., 18: 126.

Ashrafi, M., S. Nazifi, F. Namazi, N. Nasrin Kazemipour, B. Karimi, T. Goudarzi and S. Talebanzadeh, 2017. Renal protective effect of saffron aqueous extract in streptozotocin induced diabetic rats. Int. J. Med. Res. Health Sci., 6: 151-161.

Atalay, M. and D.E. Laaksonen, 2002. Diabetes, oxidative stress and physical exercise. J. Sports Sci. Med., 1: 1-14.

Azizidoost, S., Z. Nazeri, A. Mohammadi, G. Mohammadzadeh, M. Cheraghzadeh, A. Jafari and A. Kheirollah, 2019. Effect of hydroalcoholic ginger extract on brain HMG-CoA reductase and CYP46A1 levels in streptozotocin-induced diabetic rats. Avicenna J. Med Biotechnol., 11: 234238.

Babu, P.S. and K. Srinivasan, 1997. Hypolipidemic action of curcumin, the active principle of tumeric (Curcuma longa) in streptozotocin induced diabetic rats. Mol Cell Biochem., 166: 169-175. 
Babu, S.R. and P.K. Goud, 2018. Evaluation of anti-hyperlipidemic and antioxidant activity of ethanolic extract of Delonix elata on high-fat diet induced rats. Res. J. Pharmacogn. Phytochem., 12: 97-107.

Balasubashini, M.S., R. Rukkumani, P. Viswanathan and V.P. Menon, 2004. Ferulic acid alleviates lipid peroxidation in diabetic rats. Phytother. Res., 18: 310-314.

Baquer, N.Z., D. Gupta and J. Raju, 1988. Regulation of metabolic pathways in liver and kidney during experimental diabetes: effects of antidiabetic compounds. Indian J. Clin. Biochem., 13:63-80.

Banerjee, A., S. Singh, S.K. Prasad, S. Kumar, O. Banerjee, T. Seal, S. Mukherjee and B.K. Maji, 2019. Protective efficacy of Tinospora sinensis against streptozotocin induced pancreatic islet cell injuries of diabetic rats and its correlation to its phytochemical profiles. J. Ethnopharmacol., 25: 112356.

Baynes, J.W., 1991. Role of oxidative stress in development of complication in diabetes. Diabetes, 40: 405-412.

Brownlee, M., 2005. The pathophysiology of diabetic complications, a unifying mechanism. Diabete, 54: 1615-1625.

Cuchillo, H.M., C. Puga Delgadillo, Wrage-Mönning N., M.J.G. Espinosa, B.S. Montaño, A. Navarro-Ocaña, J.A. Ledesma, M.M. Díaz, and R.F. Pérez-Gil, 2013. Chemical composition, antioxidant activity and bioactive compounds of vegetation species ingested by goats on semiarid rangelands. J. Anim. Feed Sci., 22: 106-115.

Delgadillo Puga, C., H.M. Cuchillo, J.G. Espinosa Mendoza, O. Medina Campos, E. Molina Jijón, M. Díaz Martínez, M.A. Álvarez Izazaga, J.Á. Ledesma Solano and J. Pedraza Chaverri, 2015. Antioxidant activity and protection against oxidative-induced damage of Acacia shaffneri and Acacia farnesiana pods extracts: in vitro and in vivo assays. BMC Complement. Altern. Med., 15: 435.

Eddouks, M., H. Jouad, M. Maghrani, A. Lemhadri and R. Burcelin, 2003. Inhibition of endogenous glucose production accounts for hypoglycemic effect of Spergularia purpurea in streptozotocin mice. Phytomedicine, 10: 594-599.

El-Demerdash, F.M., M.I. Yousef and N.I.A. El-Naga, 2005. Biochemical study on the hypoglycemic effects of onion and garlic in alloxan-induced diabetic rats. Food Chem. Toxicol., 43: 57-63.

Franz, M.J., J.P. Bantle, C.A. Beebe, J.D. Brunzell, J.L. Chiasson, A. Grag, L.A. Holzmeister, B. Hoogwerf, E. Mayer-Davis, A.D. Mooradian, J.Q. Purnell and M. Wheeler; American Diabetes Association. 2003. Evidence-based nutrition principles and recommendations for the treatment and prevention of diabetes and related complications. Diabetes Care, 26: S51-S61.

García-Lafuente, A., E. Guillamón, A. Villares, M.A. Rostagno and J.A. Martínez, 2009. Flavonoids as anti-inflammatory agents: implications in cancer and cardiovascular disease. Inflamm Res., 58: 537-552.

Helal, E.G.E., N.A. Aouf, A.M. Khattab and M.A. Zoair, 2014. Antidiabetic effect of Artemisia annua (kaysoum) in alloxan-induced diabetic rats. Egypt. J. Hosp. Med., 57: 422-430.

Ito, F., Y. Sono and T. Ito, 2019 Measurement and clinical significance of lipid peroxidation as a biomarker of oxidative stress: Oxidative stress in diabetes, atherosclerosis, and chronic inflammation. Antioxidants (Basel), 8: 72.

Jiang, X., S. Teng, X. Wang, S. Li, Y. Zhang and D. Wang, 2018. The antidiabetic and antinephritic activities of Tuber melanosporum via modulation of Nrf2-mediated oxidative stress in the $\mathrm{db} / \mathrm{db}$ mouse. Oxid. Med. Cell. Longev., 2018: 7453865.

Judzewitsch, R.G., M.A. Pfeifer, J.D. Best, J.C. Beard, J.B. Halter and. P.D. Jr, 1982. Chronic chlorpropamide therapy of non-insulin-dependent diabetes augments basal and stimulated insulin secretion by increasing islet sensitivity to glucose. J. Clin. Endocrinol. Metab., 55: 321328.

Kajimoto, Y. and H. Kaneto, 2004. Role of oxidative stress in pancreatic $\beta$-cell dysfunction. Ann. N. Y. Acad. Sci., 1011:168-176.

Khavandi, K., H. Amer, B. Ibrahim and J. Brownrigg, 2013. Strategies for preventing type 2 diabetes: an update for clinicians. Ther. Adv. Chronic Dis., 4: 242-261. 
Krishnappa, P., K. Venkatarangaiah, S.K. Venkatesh, Shimoga Rajanna and R. Kayattukandy Balan, 2016. Wound healing activity of Delonix elata stem bark extract and its isolated constituent quercetin-3-rhamnopyranosyl-(1-6) glucopyranoside in rats. J. Pharm. Anal., 6: 389-395.

Kulkarni, R., J Acharya, S. Ghaskadbi and P. Goel, 2014. Oxidative stress as a covariate of recovery in diabetes therapy. Front. Endocrinol., 5: 89-92.

Leiter, L.A., J. Genest, S.B. Harris, G. Lewis, R. McPherson, G. Steiner and V. Woo, 2006. Dyslipidemia in adults with diabetes. Can. J. Diabetes, 30: 230-240.

Lenzen, S., 2008. Oxidative stress: The vulnerable beta-cell. Biochem Soc. Transact., 36: 343-347.

Luippold, G., J. Bedenik, A Voigt. and R. Grempler, 2016. Short- and longterm glycemic control of streptozotocin-induced diabetic rats using different insulin preparations. PLoS One. 11: e0156346.

Maghrain, M., A. Lemhadri, N.A. Zeggwagh, M. El-Amraoui, M. Haloui, H. Jouad and M. Eddouks, 2004. Effects of an aqueos extract of Triticum repens on lipid metabolism in normal and recentonset diabetic rats. J. Ethnopharmacol., 90: 331-336.

Mahajan, R.D. and B. Mishra, 2011. Using Glycated Hemoglobin HbA1C for diagnosis of Diabetes mellitus: An Indian perspective. Int. J. Biol. Med. Res., 2: 508-512.

Maritim, A.C., R.A. Sanders and J.B. Watkins, 2003. 3rd Diabetes, oxidative stress, and antioxidants: A review. J. Biochem. Mol. Toxicol., 17: 24-38.

Mathe, D., 1995. Dyslipidemia and diabetes: animal models. Diabetes Metab., 21: 106-111. Neethu, P., Haseena P., ZevaluKezo, S.R. Thomas, S.W. Goveas and A. Abraham, 2014. Antioxidant properties of Coscinium fenestratum stem extracts on Streptozotocin induced type 1 diabetic rats. J. Appl. Pharm. Sci., 4: 29-32.

Obrosova, I.G., A.G. Minchenko, R. Vasupuram, L. White, O.I. Abatan, A.K. Kumagai, R.N. Frank and M.J. Stevens, 2003. Aldose reductase inhibitor fidarestat prevents retinal oxidative stress and vascular endothelial growth factor overexpression in streptozotocin-diabetic rats. Diabetes, 52: 864-871.

Oguntibeju, O.O., 2019. Type 2 diabetes mellitus, oxidative stress and inflammation: examining the links. Int. J. Physiol. Pathophysiol. Pharmacol. 11: 45-63.

Ohkawa, H., W. Ohishi and K. Yagi, 1979. Assay for lipid peroxides in animal tissues by thiobarbituric acid reaction. Anal. Biochem., 95: 351-358.

Padalkar, R. K., A.V. Shinde and S.M. Patil, 2012. Lipid profile, serum malondialdehyde, superoxide dismutase in chronic kidney diseases and Type 2 diabetes mellitus. Biomed. Res., 23: 207-210.

Omodanisi, E.I., Y.G. Aboua and O.O. Oguntibeju, 2017. Assessment of the anti-hyperglycaemic, anti-inflammatory and antioxidant activities of the methanol extract of Moringa oleifera in diabetes-induced nephrotoxic male Wistar rats. Molecules, 22: 439.

Paglia, D.E. and W.N. Valentine, 1967. Studies on the quantitative and qualitative characterization of erythrocyte glutathione peroxidase. J. Lab. Clin. Med., 70: 158-169.

Pari, L. and M. Amarnath Satheesh, 2004. Antidiabetic activity of Boerhaavia diffusa L.: Effect on hepatic key enzymes in experimental diabetes. J Ethnopharmacol., 91:109-113.

Postic, C., R. Dentin and J. Girard, 2004. Role of the liver in the control of carbohydrate and lipid homeostasis. Diabetes Metab., 30: 398-408.

Rajagopal, K. and K. Sasikala, 2008. Antihyperglycaemic and antihyperlipidaemic effects of Nymphaea stellata in alloxan-induced diabetic rats. Singapore Med J., 49: 137-141.

Rajasekaran, S., K. Ravi, K. Sivagnanam and S. Subramanian, 2006. Beneficial effects of Aloe vera leaf gel extract on lipid profile status in rats with streptozotocin diabetes. Clin. Exp. Pharmacol. Physiol., 33: 232-237.

Robert, A.A., M.A. Al Dawish, R. Braham, M.A. Musallam, A.A. Al Hayek and N.H. Al Kahtany, 2017. Type 2 diabetes mellitus in Saudi Arabia: Major challenges and possible solutions. Curr. Diabetes Rev., 13: 59-64.

Saeed, M.K., Y. Deng and R. Dai, 2008. Attenuation of biochemical parameters in streptozotocininduced diabetic rats by oral administration of extracts and fractions of Cephalotaxus sinensis. J. Clin. Biochem. Nutr., 42: 21-28.

Sánchez, E., N. Heredia, M.R. del Camacho-Corona and S. García, 2013.Isolation, characterization and mode of antimicrobial action against Vibrio cholerae of methyl gallate isolated from Acacia farnesiana. J. Appl. Microbiol., 115: 1307-1316. 
Schuster, D., C. Laggner and T. Langer, 2005. Why drugs fail--a study on side effects in new chemical entities. Curr. Pharm. Des., 11: 3545-3559.

Sekar, S.D., K. Sivagnanam and S. Subramanian, 2005. Antidiabetic activity of Momordica charantia seeds on streptozotocin induced diabetic rats. Pharmazie, 60: 383-387.

Sepici-Dincel, A., Ş. Açikgöz, C. Çevik, M. Sengelen and E. Yeşilada, 2007. Effects of in vivo antioxidant enzyme activities of myrtle oil in normoglycaemic and alloxan diabetic rabbits. J. Ethnopharmacol., 110: 498-503.

Sirwalkar, A., K. Rajendran, C.D. Kumar and R. Bodla, 2004. Antidiabetic activities of aqueous leaf extract of Annona squamosa in streptozotocin-nicotonamide type 2 diabetic rats. J. Ethnopharmacol., 91: 171-175.

Swamy, S.K., N.C. Nagalakshmi, K. Santhosh and H.S. Yogesh, 2018. Hypoglycemic activity of ethanol extract of Jasminum grandiflorum flowers in vivo and cytotoxicity of its chloroform isolate in vitro. J. Diabetes Metab. Dis., 3: 1-9.

Swanston-Flatt, S.K., C. Day, C.J. Bailey and P.R. Flatt, 1990. Traditional plant treatments for diabetes. Studies in normal and streptozotocin diabetic mice. Diabetologia, 33: 462-464.

Tian, Z., J. Wang, Y. Wang, M. Zhang and Y. Zhou, 2017. Effects of butylphthalide on cognitive decline in diabetic rats. Mol. Med. Rep., 16: 9131-9136.

Tomkin, G.H., 2008. Targets for intervention in dyslipidemia in diabetes. Diabetes Care, 31: S241S248.

Wang, F., Y. Xi, W. Liu, J. Li, Y. Zhang, M. Jia, Q. He, H. Zhao and S. Wang, 2019. Sanbai melon seed oil exerts its protective effects in a diabetes mellitus model via the Akt/GSK-3 $\beta / \mathrm{Nrf} 2$ pathway. J. Diabetes Res., 2019: 5734723.

Wang, J., W. Hu, L. Li, X. Huang, Y. Liu, D. Wang and L. Teng, 2017. Antidiabetic activities of polysaccharides separated from Inonotus obliquus via the modulation of oxidative stress in mice with streptozotocin-induced diabetes. PLoS One, 12: e0180476.

Yeh, G.Y., D.M. Eisenberg, T.J. Kaptchuk and R.S. Phillips, 2003. Systematic review of herbs and dietary supplements for glycemic control in diabetes. Diabetes Care, 26: 1277-1294.

Yin, J., H. Zhang and J. Ye, 2008. Traditional Chinese medicine in treatment of metabolic syndrome. Endocr. Metab. Immune. Disord. Drug Targets, 8: 99-111.

Yuan, H., Q. Ma, L. Ye and G. Piao, 2016. The traditional medicine and modern medicine from natural products. Molecules, 21: 599.

Zhang, N., H. Wei, W. Wu, P. Lin, Y. Chen, Z. Liu, H. Wang, Y. Bian, K. Yu, S. Lin, Y. Cui, R. Luo, J. Lin and X. Chen, 2019. Effect of ropivacaine on peripheral neuropathy in streptozocin diabetes-induced rats through TRPV1-CGRP pathway. Biosci Rep., 2019: BSR20190817. 